\title{
Breast carcinoma detection modes and death in a female population in relation to population-based mammography screening
}

\author{
Tytti Sarkeala ${ }^{{ }^{*}}$, Tapio Luostarinen ${ }^{2}$, Tadeusz Dyba ${ }^{2}$ and Ahti Anttila ${ }^{1}$
}

\begin{abstract}
Purpose: Associations between population-based screening, breast carcinoma detection modes and breast carcinoma death have not been studied using nationwide data at individual level. We evaluated these in Finland, where invitational age is gradually expanding from 50-59 to 50-69 years in 2008-2017. We also predicted breast carcinoma patterns in 2020 to assess the impact of changing invitational policy on breast carcinoma incidence and mortality.

Methods: The data included breast carcinomas in 2000-2010 ( $n=48$ 040), and deaths due to these carcinomas ( $n=4722$ ). We divided carcinomas into those detected before or after the screening age, and those detected at the screening age. The latter was further divided into screen-detected and interval carcinomas, and carcinomas in the non-attendees. The prediction of future patterns was based on incidence data from the ten-year period 1998-2007 preceding the period of expanding invitational age in the national programme.

Results: Approximately $13 \%$ of in situ carcinomas were detected before, $29 \%$ after, and $57 \%$ at the screening age. In invasive cancers, the percentages were $16 \%, 42 \%$, and $42 \%$, respectively. At the screening age, more than half of invasive cancers were screening-detected, one quarter interval cancers, and one out of six cancers in the non-attendees. Almost $60 \%$ of breast cancer deaths were due to cancers detected after the screening age. By 2020, breast cancers detected at the screening age will increase from $42 \%$ to $65 \%$, and breast cancers detected by screening from $23 \%$ to $38 \%$.

Conclusions: The study demonstrates a novel approach to examine associations between breast carcinoma incidence and mortality within and outside population-based screening. The results show mammography screening having a distinct role in overall breast carcinoma incidence and mortality.
\end{abstract}

Keywords: Breast cancer; Mammography; Screening; Population; Detection

\section{Introduction}

Population-based mammography screening is a multistep process starting with identification and invitation of the target population, and continuing further to mammography test, and prospective recall examinations, cancer management and care (Vainio and Bianchini 2002; Perry et al. 2008). In the screening target population, breast cancers are detected among attendees within the screening programme, or outside the programme either among non-attendees or among attendees without findings in their previous screening episode. Additionally, a considerable amount of breast carcinomas are detected in women

\footnotetext{
* Correspondence: tytti.sarkeala@cancer.fi

${ }^{1}$ Mass Screening Registry/Finnish Cancer Registry, Unioninkatu 22, Helsinki 00130, Finland

Full list of author information is available at the end of the article
}

who not yet have reached, or already have passed, the screening age.

Monitoring of the European population-based mammography screening has shown significant variation between programmes and centres in invitational coverage, attendance, and sensitivity and specificity of screening (Sarkeala et al. 2004; Giordano et al. 2012; Hofvind et al. 2012). Relationships between the screening process (recall rate), the screening performance (sensitivity), and the mortality reduction due to screening have also been shown to be non-straightforward (Sarkeala et al. 2006). The above imply delicate balance between benefits and harms in the European population-based mammography screening.

Variation in the screening performance (Sarkeala et al. 2006; Törnberg et al. 2010) - as well as in the coverage 
of screening - affects the ratio of breast carcinomas detected within and outside the organised screening. Furthermore, a considerable percentage of breast carcinomas detected outside screening may be asymptomatic with a prognostic profile comparable to that of the screendetected carcinomas (Sarkeala et al. 2004; 2006; Hoff et al. 2012). Hence it is important to assess the detection of breast carcinomas in the whole female population.

Albeit recommended by the European Network of Cancer Registries (European Network for Cancer Registries 2014), only few European countries have so far assessed the impact of population-based mammography screening on the distribution of all breast carcinomas. This would, however, help to assess associations between breast carcinoma diagnostics and treatment, and to clarify impacts of population-based mammography screening on breast carcinoma incidence and mortality.

The aim of the current study is to examine detection modes of incident breast carcinomas and breast carcinoma deaths in relation to invitation and participation to population-based mammography screening. The study uses all breast carcinomas among Finnish women in 2000-2010, and deaths due to these carcinomas. Additionally, the study analyses distribution and trend of breast carcinomas in areas practicing various invitational policies, and predicts breast cancer patterns in 2020, when the national mammography programme in Finland will cover all women aged 50-69 years.

\section{Material and methods}

In Finland, population-based mammography screening was started gradually in 1986-1987. The screening programme was fully implemented in the beginning of 1992 for all women aged 50-59 years. Detailed description of the programme has been given earlier (Sarkeala et al. 2004; 2006). Based on the Government Degree on Screenings from 2007, the invitational age of the screening programme is gradually expanding from 50-59 years to 50-69 years (Government Decree on Screenings (1339/2006)). Women born in 1947 are the first to receive a regular, biennial invitation until the age of 69 years. In the study period 2000-2010, the Finnish municipalities thus have invited all women aged 50-59 years regularly, and women aged 60-69 years by an annually expanding protocol to population-based mammography screening. The city of Turku, however, has carried out an exceptional invitational protocol throughout $2000-2010$ by inviting women aged 50-69 years regularly and women aged 40-49 and 70-74 years irregularly to mammography screening.

Since the start of the national programme, the data on mammography screening have been registered centrally to the Mass Screening Registry. The coverage of registration has increased steadily from $70 \%$ to more than 98\% from the early 1990's (Mass Screening Statistics in
Finland 2014). The clinical and pathological data on all breast carcinomas in Finland have been recorded by the Finnish Cancer Registry since 1953.

We assessed the detection of all breast carcinomas diagnosed in Finland in the period 2000-2010 ( $\mathrm{n}=48$ 040) by linking information on breast carcinomas and on screening invitations and findings at an individual level. To assess relationships between breast cancer detection and breast cancer death, we also linked the incident breast carcinoma cases with deaths from breast cancer in 2000-2010. The linkage was done using a unique personal identifier (social security number) as a key. Within this linkage procedure, we divided breast carcinomas into three categories: carcinomas detected before or after the screening age (before the first and after the last invitation to screening) and carcinomas detected at the screening age. The categorization was based on novel recommendations on the categories of detection, developed in an expert work group in a cancer-registry-driven Eurocourse project (EUROCOURSE: EUROpe against Cancer 2014). A similar assessment has earlier been reported for cervical carcinomas in Finland (Lönnberg et al. 2013).

Carcinomas detected at the screening age were further divided into screen-detected carcinomas, interval carcinomas, carcinomas among the non-attendees, and carcinomas among women, whose data on screening invitations and results had not been sent to the Mass Screening Registry (non-registered carcinomas). Screen-detected carcinomas were carcinomas diagnosed among the screening attendees within six months after the previous population-based mammography test with a positive result both from the test and the recall examinations. Interval carcinomas were carcinomas diagnosed among the screening attendees in between two subsequent invitations with a) a negative result from the previous test, b) a positive result from the previous test and a negative result from the previous recall examinations, or c) a positive result from the previous test and the recall examinations with a date of diagnosis six months after the date of mammography (women having both screen-detected and interval breast cancers).

We report the incident breast carcinoma categories by behaviour (in situ carcinoma of the breast; invasive carcinoma i.e. breast cancer), morphology (ductal, lobular, others), and stage (local, metastasized, unknown). The ductal carcinomas are those with ICD-O-3-codes M850007, and lobular carcinomas those with an ICD-O3-code M8520. The metastasized breast cancers are those metastasized to regional lymph nodes only (regional metastasis) or further and/or to adjacent tissues (distant metastasis).

To examine the proportions of screen-detected and interval breast cancers and breast cancers among the non-attendees out of all breast cancers in the screening target population in 2000-2010, we applied Poisson 
regression. Period wise (2000-2002 (reference period), 2003-2006, and 2007-2010) estimates of incidence rate ratio (IRR) were adjusted for categorical age (50-54, 55-59, 60-64, and 65-69 years).

Based on the varying invitational policies between the rest of Finland and the Turku area in 2000-2010, and incidence prediction by an additive Poisson model (Dyba and Hakulinen 1994), we estimated the distribution of invasive breast cancers in Finland in 2020, when all women aged 50-69 years are expected to get an invitation to mammography screening in every two years (Government Decree on Screenings (1339/2006)). The Poisson model allowed for different age-specific changes of incidence rates on an additive scale over time (Dyba and Hakulinen 2000). The prediction was based on breast cancer incidence in ages 30-89 years in the ten-year period 1998-2007 preceding the expansion period of the invitational age in the national screening programme. The predicted, age-specific numbers of breast cancers in ages 30-89 years in 2020 were divided into breast carcinoma categories using information on breast cancer detection from 2000-2010 from Turku area for ages 60-79 years, and corresponding information from the rest of Finland for ages less than 60 and more than 79 years.

\section{Results}

A total of 3468 in situ carcinomas and 44572 invasive breast cancers were diagnosed in Finland in 2000-2010
(Figure 1a). Approximately $13 \%$ of in situ carcinomas were detected before the first, $29 \%$ after the last invitation to screening, and $57 \%$ at the screening age. In invasive cancers, the corresponding percentages were $16 \%, 42 \%$, and $42 \%$. At the screening age, more $55 \%$ of the invasive breast cancers were detected by screening, $28 \%$ as interval cancers, and $14 \%$ among the non-attendees. In Turku area, where women aged 50-69 had been invited regularly to mammography screening throughout 2000-2010, most invasive breast cancers (64\%) were detected at the screening age (Figure 1b).

At the screening age, most breast carcinomas were detected in ages 50-69 years (Table 1). Few cases in age groups less than 50 and over 69 years were detected in Turku city, where the age groups $40-49$ and $70-74$ years had been invited to population-based screening irregularly in 2000-2007. Most interval cancers were due to negative result from the mammography test.

Localized (63\%) and regionally metastasized (29\%) were the most common stages of screen-detected cancers (Table 2). In breast cancers among the non-attendees, the corresponding proportions were $43 \%$ and $36 \%$, and in the interval breast cancers $49 \%$ and $38 \%$, respectively, showing that stages with a favourable prognosis were largely diagnosed in the screening target population also outside the screening programme. The stage distribution of breast cancers detected before the screening age resembled to that of the non-attendees (with less progressed a

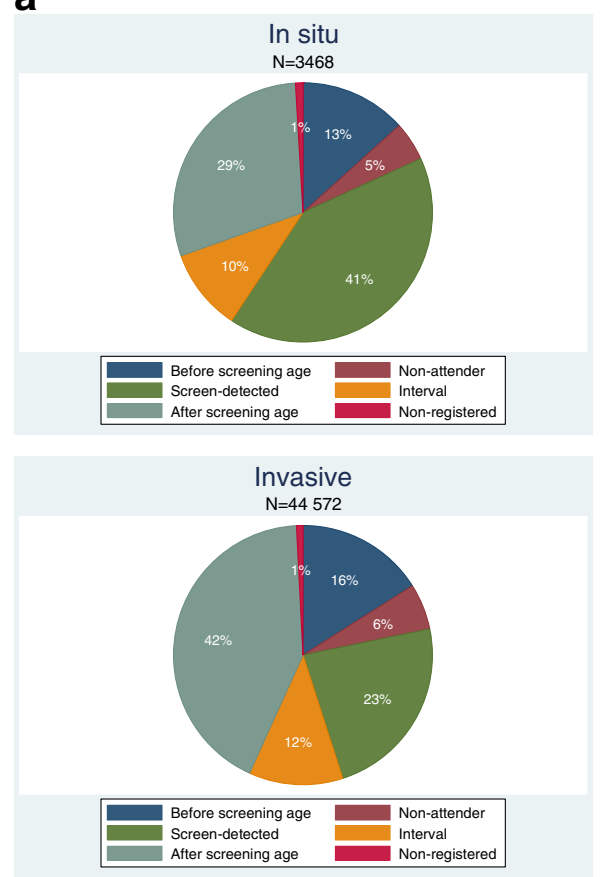

b

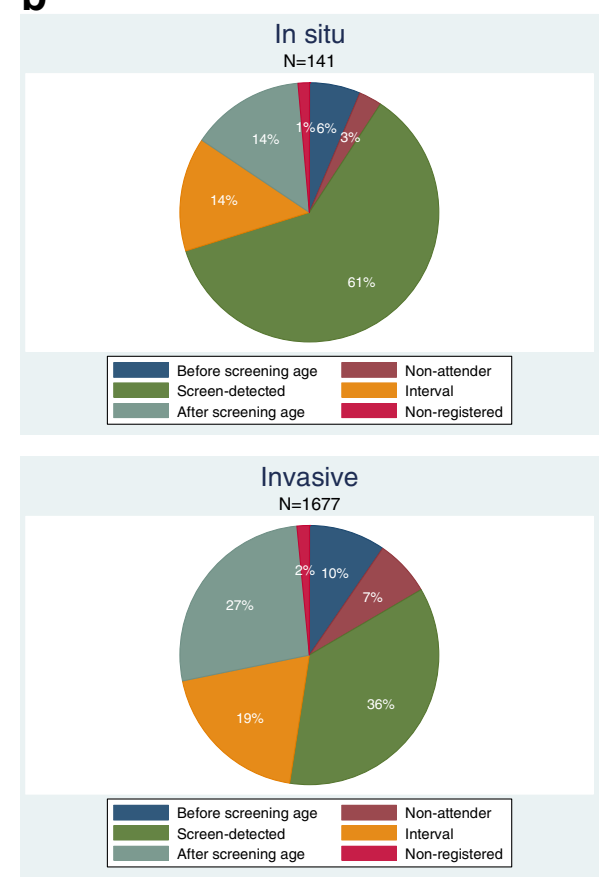

Figure 1 Breast carcinoma detection modes in 2000-2010. (a) In situ breast carcinomas and invasive breast cancers in relation to invitation to screening in the whole country. (b) In situ breast carcinomas and invasive breast cancers in relation to invitation to screening in the Turku area. 
Table 1 Breast carcinomas by behaviour and age in relation to invitation to screening in the screening target population in 2000-2010

\begin{tabular}{|c|c|c|c|c|c|c|c|c|}
\hline & \multicolumn{8}{|c|}{ In situ } \\
\hline & \multicolumn{2}{|c|}{$<50$ yrs } & \multicolumn{2}{|c|}{$50-69$ yrs } & \multicolumn{2}{|c|}{$>69$ yrs } & \multicolumn{2}{|l|}{ Total } \\
\hline & $\mathrm{N}$ & (\%) & $\mathrm{N}$ & $(\%)$ & $\mathrm{N}$ & (\%) & $\mathrm{N}$ & (\%) \\
\hline ALL & 19 & $(100)$ & 1948 & $(100)$ & 18 & (100) & 1985 & (100) \\
\hline Non-attendee & 2 & $(11)$ & 165 & (9) & 2 & (11) & 169 & (9) \\
\hline Screen-detected & 9 & $(47)$ & 1411 & $(72)$ & 7 & (39) & 1427 & $(72)$ \\
\hline Interval & 2 & $(11)$ & 346 & (18) & 8 & (44) & 356 & (18) \\
\hline test- & 2 & $(11)$ & 252 & (13) & 6 & (33) & 260 & (13) \\
\hline test+, recall- & - & $(-)$ & 61 & (3) & 2 & (11) & 63 & (3) \\
\hline test + , recall+, dg $>6$ mths & - & $(-)$ & 33 & $(2)$ & - & $(-)$ & 33 & $(2)$ \\
\hline \multirow[t]{4}{*}{ Non-registered } & 6 & $(32)$ & 26 & $(1)$ & 1 & (6) & 33 & (2) \\
\hline & \multicolumn{8}{|c|}{ Invasive } \\
\hline & \multicolumn{2}{|c|}{$<50$ yrs } & \multicolumn{2}{|c|}{ 50-69 yrs } & \multicolumn{2}{|c|}{$>69 \mathrm{yrs}$} & \multicolumn{2}{|l|}{ Total } \\
\hline & $\mathrm{N}$ & $(\%)$ & $\mathrm{N}$ & $(\%)$ & $\mathrm{N}$ & (\%) & $\mathbf{N}$ & $(\%)$ \\
\hline ALL & 227 & $(100)$ & 18139 & $(100)$ & 198 & (100) & 18564 & $(100)$ \\
\hline Non-attendee & 31 & (14) & 2512 & $(14)$ & 31 & (16) & 2574 & $(14)$ \\
\hline Screen-detected & 70 & $(31)$ & 10242 & $(56)$ & 70 & (35) & 10382 & $(56)$ \\
\hline Interval & 46 & (21) & 5093 & (28) & 95 & (48) & 5234 & (28) \\
\hline test- & 42 & $(19)$ & 4529 & $(25)$ & 80 & (40) & 4651 & $(25)$ \\
\hline test+, recall- & 4 & $(2)$ & 479 & (3) & 9 & (5) & 492 & (3) \\
\hline test + , recall+, dg $>6$ mths & - & $(-)$ & 85 & $(<1)$ & 6 & (3) & 91 & $(<1)$ \\
\hline Non-registered & 80 & (35) & 292 & (2) & 2 & (1) & 374 & (2) \\
\hline
\end{tabular}

metastasized tumours), and the distribution of breast cancers detected after the screening age to that of the interval breast cancers (Table 2). The morphological distribution of invasive breast cancers was similar within and outside the programme.

The absolute numbers of in situ carcinomas and invasive breast cancers increased clearly from 2000 to 2010
(Figure 2a). At the screening age, the proportion of interval breast cancers was $13 \%$ lower in the expansion period 2007-2010 compared to the period 2000-2002 (IRR 0.87, 95\% confidence interval (CI) 0.81-0.93\%) (Figure 2b, Table 3 ). This was, however, mainly attributable to the ages 60-69 years (Table 3). The increase in the proportion of breast cancers among the non-attendees

Table 2 Invasive breast cancers by stage and morphology in relation to invitation to screening in 2000-2010

\begin{tabular}{|c|c|c|c|c|c|c|c|c|c|c|c|c|c|c|}
\hline & \multirow{2}{*}{\multicolumn{2}{|c|}{ Before screening age }} & \multicolumn{8}{|c|}{ At screening age } & \multicolumn{2}{|c|}{ After screening age } & \multicolumn{2}{|l|}{ Total } \\
\hline & & & \multicolumn{2}{|c|}{ Non-attendees } & \multicolumn{2}{|c|}{ Screen-detected } & \multicolumn{2}{|c|}{ Interval } & \multicolumn{2}{|c|}{ Non-registered } & \multirow[b]{2}{*}{$\mathrm{N}$} & \multirow[b]{2}{*}{ (\%) } & \multirow[b]{2}{*}{$\mathrm{N}$} & \multirow[b]{2}{*}{$(\%)$} \\
\hline & $\mathbf{N}$ & $(\%)$ & $\mathbf{N}$ & $(\%)$ & $\mathbf{N}$ & (\%) & $\mathbf{N}$ & (\%) & $\mathrm{N}$ & $(\%)$ & & & & \\
\hline ALL & 7129 & $(100)$ & 2574 & $(100)$ & 10382 & $(100)$ & 5234 & (100) & 374 & $(100)$ & 18879 & $(100)$ & 44752 & (100) \\
\hline Local & 3056 & $(42)$ & 1110 & $(43)$ & 6495 & (63) & 2563 & (49) & 195 & (52) & 9089 & (48) & 22508 & (50) \\
\hline Metastasis & 3698 & (51) & 1272 & $(50)$ & 3290 & (31) & 2392 & (46) & 157 & $(42)$ & 7881 & $(42)$ & 18690 & \\
\hline regional & 3140 & $(44)$ & 938 & (36) & 3024 & (29) & 2015 & (38) & 138 & (37) & 5695 & (30) & 14950 & $(42)$ \\
\hline distant & 427 & (6) & 284 & $(11)$ & 144 & (1) & 280 & (5) & 17 & (5) & 1740 & (9) & 2892 & (6) \\
\hline not specified & 131 & (1) & 50 & (3) & 122 & (1) & 97 & (3) & 2 & $(<1)$ & 446 & (2) & 848 & (2) \\
\hline Unknown & 375 & $(7)$ & 192 & $(7)$ & 597 & (6) & 279 & (5) & 22 & $(6)$ & 1909 & (10) & 3374 & (8) \\
\hline Ductal & 5586 & (78) & 1866 & $(72)$ & 7976 & (77) & 3767 & (72) & 287 & (77) & 13164 & (70) & 32646 & (73) \\
\hline Lobular & 1010 & (14) & 426 & (17) & 1672 & (16) & 1037 & (20) & 66 & (18) & 3395 & (18) & 7606 & (17) \\
\hline Others & 533 & (8) & 282 & (11) & 734 & (7) & 430 & (8) & 21 & (5) & 2320 & (12) & 4320 & (10) \\
\hline
\end{tabular}



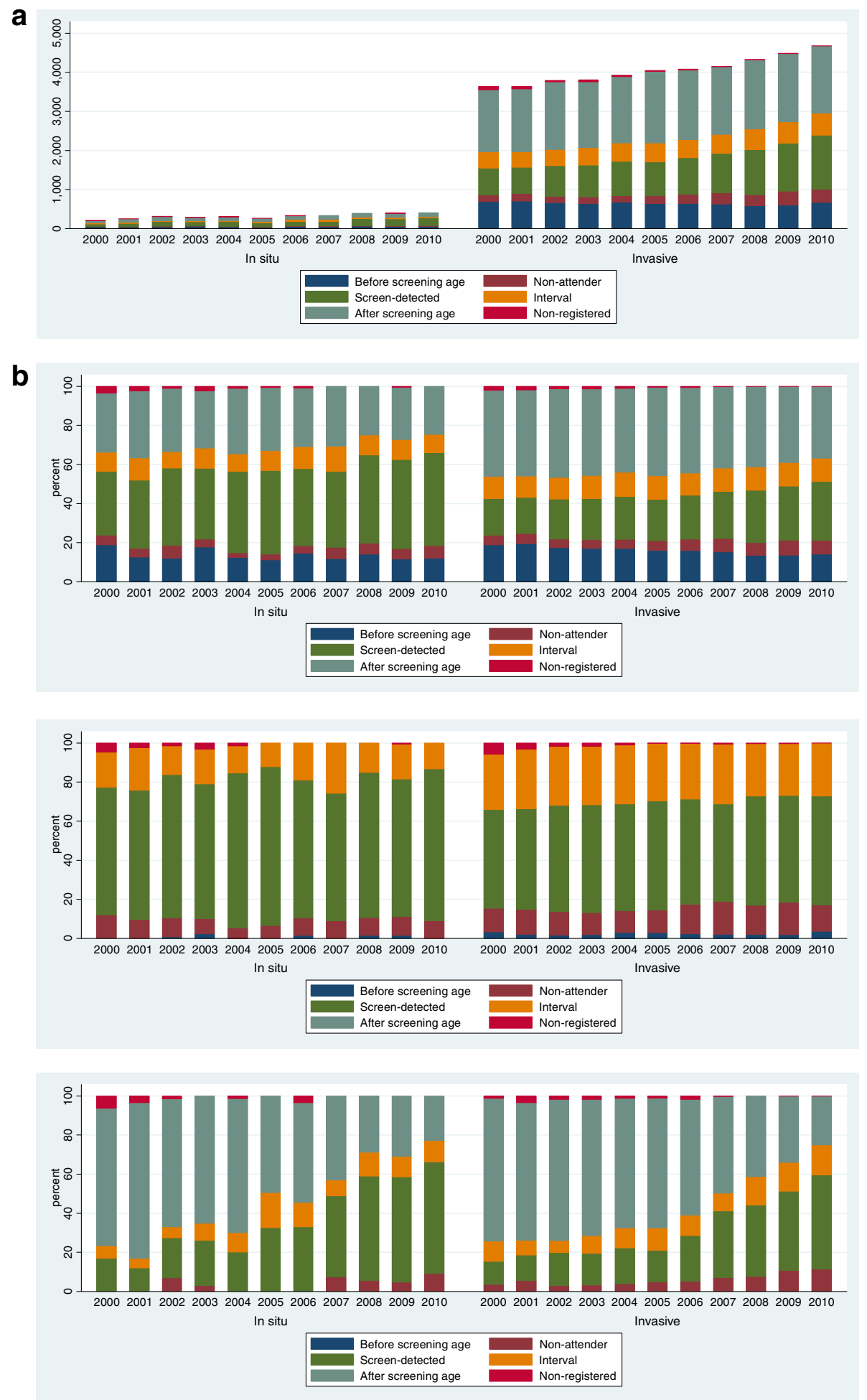

Figure 2 Breast carcinoma detection modes over 2000-2010. (a) Absolute numbers of in situ breast carcinomas and invasive breast cancers in relation to invitation to screening, all ages. (b) Proportion of in situ breast carcinomas and invasive breast cancers in relation to invitation to screening; all ages, ages 50-59, and ages 60-69 years. 
Table 3 Development of breast cancers among the nonattendees, screen-detected breast cancers, and interval breast cancers from 2000-2002 to 2007-2010 (expansion period) by incidence rate ratios (IRR) with $95 \%$ confidence intervals $(95 \% \mathrm{Cl})$ in ages $50-59,60-69$, and $50-69$ years

\begin{tabular}{|c|c|c|c|c|c|}
\hline \multicolumn{6}{|l|}{ 50-59 years } \\
\hline & Non-attendee & Scre & detected & Inte & \\
\hline & $95 \% \mathrm{Cl}$ & IRR & $95 \% \mathrm{Cl}$ & IRR & $95 \% \mathrm{Cl}$ \\
\hline
\end{tabular}

\section{Period}

\begin{tabular}{|c|c|c|c|c|c|c|}
\hline $2000-2002$ & \multicolumn{2}{|l|}{1} & \multicolumn{2}{|l|}{1} & \multicolumn{2}{|l|}{1} \\
\hline $2003-2006$ & 0.98 & $0.87-1.10$ & 1.07 & $1.01-1.13$ & 0.97 & $0.90-1.05$ \\
\hline 2007-2010 & 1.23 & $1.09-1.38$ & 1.05 & $0.99-1.11$ & 0.92 & 0.85-0.99 \\
\hline \multicolumn{7}{|l|}{$60-69$ years } \\
\hline & \multicolumn{2}{|c|}{ Non-attendee } & \multicolumn{2}{|c|}{ Screen-detected } & \multicolumn{2}{|c|}{ Interval } \\
\hline & IRR & $95 \% \mathrm{Cl}$ & IRR & $95 \% \mathrm{Cl}$ & IRR & $95 \% \mathrm{Cl}$ \\
\hline
\end{tabular}

\begin{tabular}{|c|c|c|c|c|c|c|}
\hline \multicolumn{7}{|l|}{ Period } \\
\hline $2000-2002$ & \multicolumn{2}{|l|}{1} & \multicolumn{2}{|l|}{1} & \multicolumn{2}{|l|}{1} \\
\hline 2003-2006 & 0.83 & $0.65-1.06$ & 1.07 & $0.95-1.21$ & 1.09 & $0.93-1.29$ \\
\hline 2007-2010 & 1.04 & $0.84-1.29$ & 1.26 & $1.13-1.41$ & 0.77 & $0.66-0.89$ \\
\hline \multicolumn{7}{|l|}{$50-69$ years } \\
\hline & \multicolumn{2}{|c|}{ Non-attendee } & \multicolumn{2}{|c|}{ Screen-detected } & \multicolumn{2}{|c|}{ Interval } \\
\hline & IRR & $95 \% \mathrm{Cl}$ & IRR & $95 \% \mathrm{Cl}$ & IRR & $95 \% \mathrm{Cl}$ \\
\hline \multicolumn{7}{|l|}{ Period } \\
\hline $2000-2002$ & 1 & & 1 & & 1 & \\
\hline 2003-2006 & 0.95 & $0.85-1.06$ & 1.06 & $1.01-1.12$ & 0.99 & $0.93-1.07$ \\
\hline $2007-2010$ & 1.18 & $1.07-1.31$ & 1.11 & $1.05-1.16$ & 0.87 & $0.81-0.93$ \\
\hline
\end{tabular}

from 2000-2002 to 2007-2010 was more pronounced, $18 \%$ (IRR 1.18, 95\% CI 1.07-1.31) than that of the screendetected breast cancers, $11 \%$ (IRR 1.11, 95\% CI 1.05-1.16) (Table 3). The increase in non-attendees was due to ages 50-59 years (Table 3 ), which were covered by the screening programme already before the year 2000.

Compared to the study period 2000-2010, the proportion of breast cancers detected at the screening age in 2020 is, according to the prediction, going to increase from $42 \%$ to $65 \%$ (Table 4). Of these, the proportion of screen-detected and interval cancers will increase, and the proportion of breast cancers among the non-attendees will remain more or less at the same level.

When assessing breast cancer deaths in 2000-2010, those resulting from breast cancers detected throughout 2000-2010 (potential follow-up time 1-11 years, $n=4722$ ) were mostly, 59\%, due to breast cancers detected after the screening age (Figure 3). The same phenomenon was also seen in breast cancers detected during the year 2000 only (potential follow-up time 11 years, $n=724$ ). Only $7 \%$ of breast cancer deaths were due to breast cancers detected by screening. In interval cancers and cancer among the non-attendants, the corresponding proportions were $9 \%$ and $7 \%$.
Table 4 Invasive breast cancers by behaviour in relation to invitation to screening in the Finnish female population in the study period $2000-2010$ and the corresponding predicted values with $95 \%$ confidence intervals $(\mathrm{Cl})$ in 2020

\begin{tabular}{|c|c|c|c|c|c|}
\hline \multirow[b]{3}{*}{ ALL } & \multicolumn{2}{|c|}{$2000-2010$} & \multicolumn{3}{|l|}{2020} \\
\hline & $\mathrm{N}$ & (\%) & $\mathrm{N}$ & $95 \% \mathrm{Cl}$ & (\%) \\
\hline & 44572 & $(100)$ & 5454 & & (100) \\
\hline Before screening age & 7129 & (16) & 541 & $(496-589)$ & (10) \\
\hline At screening age & 18564 & $(42)$ & 3545 & (3 429-3 662) & (65) \\
\hline non-attendee & 2948 & (7) & 410 & $(371-451)$ & (8) \\
\hline screen-detected & 10291 & (23) & 2076 & (1 988-2 166) & (38) \\
\hline interval & 5325 & (12) & 1059 & (996-1 124) & (19) \\
\hline After screening age & 18879 & (42) & 1368 & (1 296-1 441) & (25) \\
\hline
\end{tabular}

\section{Discussion}

We examined all breast carcinomas in Finland in relation to invitation, attendance and findings in the populationbased mammography screening, and deaths due to these carcinomas. We also assessed the impact of the expansion of invitational age on the detection of breast carcinomas in the future. To our knowledge, the study is the first to evaluate associations between population-based screening, breast carcinoma detection and breast carcinoma death in a nationwide female population.

According to our prediction, more than $60 \%$ of invasive breast cancers will be diagnosed at the screening target age and approximately $40 \%$, respectively, directly by screening when the whole female target population aged 50 to 69 years will be invited to screening in Finland in 2020. Since breast cancers detected after the last screening round will also be affected by the preceding period of population-based screening (Day et al. 1989), screening will be involved in the characteristics of most incident breast carcinomas in 2020. Moreover, most deaths due to breast carcinoma in the study period were due to breast cancers detected after the screening age suggesting that the expanding mammography programme will also have a considerable impact on the future breast cancer mortality.

In the current data, as much as $40 \%$ of in situ breast carcinomas were detected before or after the screening age. Additionally, $10 \%$ of them were interval cancers, and $5 \%$ were detected in the non-attendees of screening. All these refer to high opportunistic activity and should be studied further. Unfortunately, the opportunistic mammography screening is not registered in Finland, and the level of this phenomenon, therefore, is difficult to measure. Other European countries have also reported increase in opportunistic activity due to population-based screening (Boncz et al. 2008).

The proportion of interval cancers in the whole screening target population was $28 \%$, and among the screening attendees 33\%. In our previous study from the 1990s and 


\section{a}

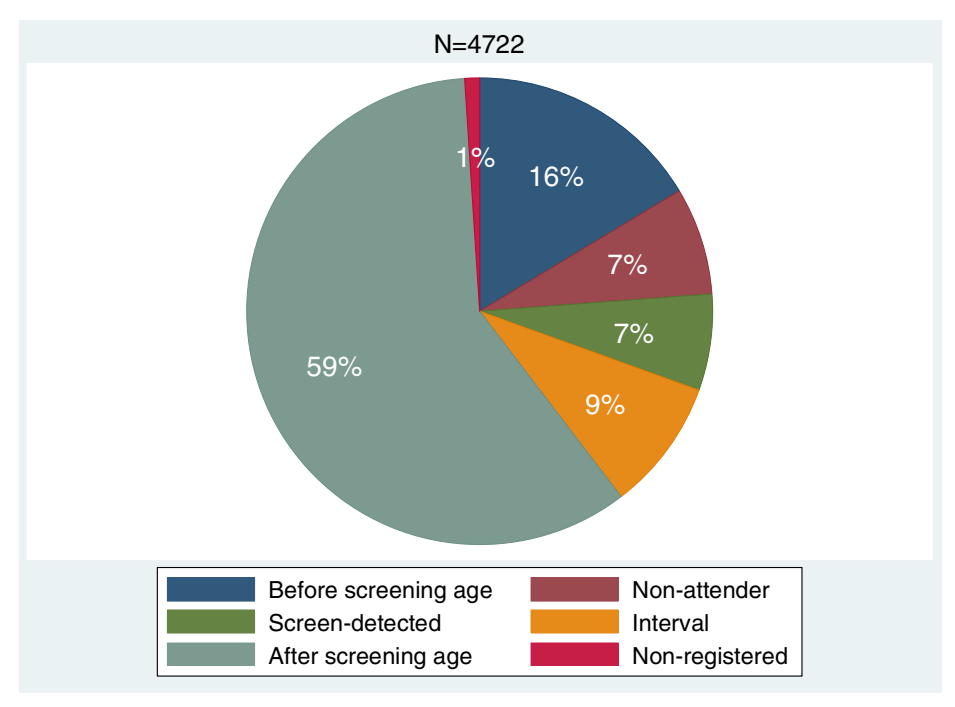

b

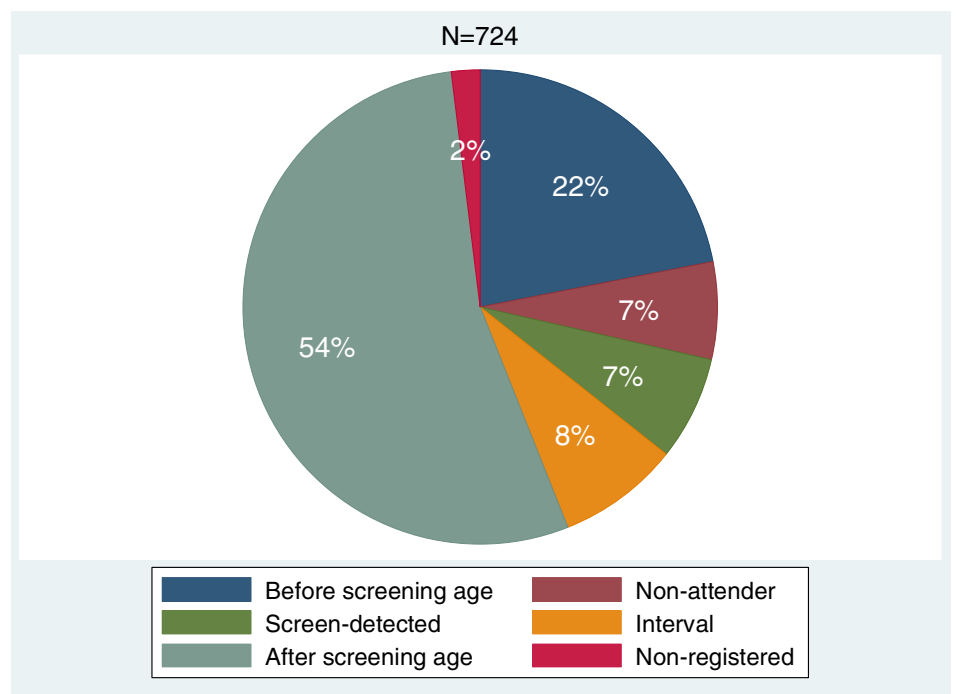

Figure 3 Death from breast cancer in relation to breast carcinoma detection modes. (a) Both diagnosis and death in 2000-2010. (b) Diagnosis in 2000, death in 2000-2010.

early 2000s, the proportion of interval cancers among the screening attendees measured by the detection method was $35 \%$, and there was an increasing trend in the interval cancer proportion (Sarkeala et al. 2006). According to the current results, the reported increase in the early 2000's seems to have turned to a decrease after the year 2007 when the expansion of invitational age in the Finnish mammography programme started. In women aged 60 69 years, the interval cancer occurrence has consistently been reported to be smaller than in the younger target population (Sarkeala et al. 2006; Törnberg et al. 2010). Nonetheless, also trends in the access to mammograms and/or other diagnostic activities outside screening may have affected the phenomenon.
The increase in the proportion of breast cancers among the non-participants - which was evident in ages 50-59 years - raises concern on the development of attendance rate in the Finnish mammography programme. According to the national statistics, overall attendance to screening has decreased during the 2000s from approximately 87 to 85 percent (Government Decree on Screenings (1339/ 2006)). Compared to other European countries, the overall rate in Finland is, however, still among the highest (Giordano et al. 2012).

Approximately $40 \%$ of breast carcinoma cases and more than half of breast cancer deaths were due to breast cancers diagnosed after the screening age. This was similarly evident in breast cancers detected in the 
study period 2000-2010 (potential follow-up time varying between 1 to 11 years) and in breast cancers detected solely during the year 2000 (potential follow-up time 11 years). In both settings, there were very few deaths due to in situ carcinoma. Also the proportion of deaths due to screen-detected cancers was small compared to the proportion they represented in the distribution of cancers (7\% vs. $23 \%$ ) whereas the proportion of deaths due to breast cancers among non-attendants (7\% vs. $6 \%)$ and due to interval breast cancers ( $9 \%$ vs. $12 \%$ ) was more or less similar to that of cancer distribution.

According to the prediction, the proportion of breast cancers detected at the screening age will increase from around $40 \%$ to more than $60 \%$ in Finland in 2020. When assessing this information in line with the information on breast cancer deaths, two issues arise. First, effectiveness of breast cancer screening will probably improve since older women will be involved in the programme - and screening has been shown to be more effective among women aged 60-69 years than at younger ages (Anttila et al. 2008; Sarkeala et al. 2008a; Sarkeala et al. 2008b; Otto et al. 2012; Njor et al. 2012). Second, expansion of invitational age to 70-74 years should be taken into consideration in future scenarios of the national programme. Women aged 70-74 years have been invited to population-based screening in the Netherlands since the early 1998, and the results on performance and mortality reduction have been encouraging (Broeders et al. 2002; Fracheboud et al. 2006). In Finland, women aged 70-74 years have previously been invited to population-based screening in the Turku city, where the most prominent reduction in breast cancer mortality was observed in the oldest age groups (Parvinen et al. 2006).

Current data will be utilized further to investigate associations between breast carcinoma diagnostics, therapeutic activities, and breast carcinoma death within and outside the screening target population (Lehtimäki et al. 2011; Haukka et al. 2011). Documentation outside the target population may e.g. provide information on reasons behind the reduction in breast cancer mortality in women aged 40-49 years (Anttila and Martin-Moreno 2013), which recently has been reported from several European countries. In the screening target population, the data can be applied to examine over-diagnosis and other disadvantages of screening (Hofvind et al. 2012; Puliti et al. 2012; Welch and Black 2010; Esserman et al. 2013; Bleyer and Welch 2012). A 1-10\% over-diagnosis in a woman's lifetime has been reported due to screening in ages 50-69 years (Puliti et al. 2012). If the excess of 10\% in breast cancer incidence was attributed only to screening, approximately $25 \%\left(10 / 38^{*} 100\right)$ of screen-detected breast cancers would represent over-diagnosis in the current data (in 2020). However, stages with a favourable prognosis were largely diagnosed also outside the organised screening in the current data. This refers that overdiagnosis may be attributed also to interval breast cancers and breast cancers detected from the non-attendees.

To conclude, screen-detected in situ and invasive carcinomas represented the largest category of breast carcinomas detected at the screening age. However, stages with favourable prognosis were largely diagnosed also outside the screening programme referring that over-diagnosis may not solely be attributed to the programme. Most breast cancer deaths were due to invasive breast cancers detected after the screening age. Due to expanding invitational age, the proportion of breast cancers detected at the screening age and by screening will substantially increase by 2020 . These imply that organised screening will have a distinct impact on overall breast cancer incidence and mortality in the future.

Our study demonstrates a novel approach for cancer registries to examine associations between breast cancer detection and deaths due to breast cancer. The approach requires, however, comprehensive data on screening and cancer deaths from nationwide, high quality registers with a $100 \%$ coverage and may therefore be unattainable for some European countries. In countries with appropriate databases, monitoring and evaluation of the impact of population-based screening on the overall cancer burden can be carried out on a regular basis.

\section{Competing interests}

The authors declare that they have no competing interests.

\section{Authors' contributions}

AA initiated the study and gave critical comments, TD carried out statistical modeling and gave critical comments, TL gave critical comments, TS constructed the data, performed statistical analyses, and wrote the manuscript. All authors read and approved the final manuscript.

\section{Author details}

${ }^{1}$ Mass Screening Registry/Finnish Cancer Registry, Unioninkatu 22, Helsinki 00130, Finland. 'Finnish Cancer Registry, Unioninkatu 22, Helsinki 00130, Finland.

Received: 3 June 2014 Accepted: 3 June 2014

Published: 8 July 2014

\section{References}

Anttila A, Martin-Moreno JM (2013) Cancer Screening. In: Successes and Failures of Health Policy in Europe. Four Decades of Divergent Trends and Converging Challenges. McGraw-Hill, Open University Press, Berkshire, England, pp 179-192

Anttila A, Sarkeala T, Hakulinen T, Heinävaara S (2008) Impacts of the Finnish service screening programme on breast cancer rates. BMC Public Health 8:38

Bleyer A, Welch $G$ (2012) Effect of three decades of screening mammography on breast cancer incidence. NEJM 367:1998-2005

Boncz I, Sebestyén A, Pintér I, Battyány I, Ember I (2008) The effect of an organized, nationwide breast cancer screening programme on nonorganized mammography activities. J Med Screen 15:14-17

Broeders MJ, Verbeek AL, Straatman H et al (2002) Repeated mammography screening reduces breast cancer mortality along the continuum of age. J Med Screen 9:163-167

Day NE, Williams DR, Khaw KT (1989) Breast cancer screening programmes: the development of a monitoring and evaluation system. Br J Cancer 59:954-958

Dyba T, Hakulinen T (1994) Precision of incidence predictions based on Poisson distributed observations. Stat Med 13:1513-1523 
Dyba T, Hakulinen T (2000) Comparison of different approaches to incidence prediction based on simple interpolation techniques. Stat Med 19:1741-1752

Esserman LJ, Thompson IM, Reid B (2013) Overdiagnosis and overtreatment in cancer. An opportunity for improvement. JAMA 310:797-798

EUROCOURSE: EUROpe against Cancer (2014) Optimisation of the Use of Registries for Scientific Excellence in research. http://www.eurocourse.org/

European Network for Cancer Registries (2014) http://www.encr.eu/

Fracheboud J, Groenewoud JH, Boer R et al (2006) Seventy-five years is an appropriate upper age limit for population-based mammography screening. Int J Cancer 118:2020-2025

Giordano L, von Karsa L, Tomatis M et al (2012) Mammographic screening programmes in Europe: organization, coverage and participation. J Med Screen 19(Suppl 1):72-82

Government Decree on Screenings (1339/2006) (2006) http://www.finlex.fi/fi/laki/ kaannokset/2006/en20061339.pdf

Haukka J, Byrnes G, Boniol M, Autier P (2011) Trends in breast cancer mortality in Sweden before and after implementation of mammography screening. PLoS One 6(9):e22422, doi:10.1371/journal.pone.0022422

Hoff SR, Klepp O, Hofvind S (2012) Asymptomatic breast cancer in nonparticipants of the national screening programme in Norway: a confounding factor in evaluation? J Med Screen 19:177-183

Hofvind S, Ponti A, Patnick J et al (2012) False-positive results in mammographic screening for breast cancer in Europe: a literature review and survey of service screening programmes. J Med Screen 19(Suppl 1):57-66

Lehtimäki T, Lundin M, Linder N et al (2011) Long-term prognosis of breast cancer detected by mammography screening or other methods. Breast Cancer Res 13:R134

Lönnberg S, Nieminen P, Luostarinen T, Anttila A (2013) Mortality audit of the Finnish cervical cancer screening program. Int J Cancer 132:2134-2140

Mass Screening Statistics in Finland (2014) http://www.cancer.fi/syoparekisteri/en/ mass-screening-registry/statistics/

Njor S, Nyström L, Moss S et al (2012) Breast cancer mortality in mammographic screening in Europe: a review of incidence-based mortality studies. J Med Screen 19(Suppl 1):33-41

Otto SJ, Fracheboud J, Verbeek AL et al (2012) Mammography screening and risk of breast cancer death: a population-based case-control study. Cancer Epidemiol Biomarkers Prev 21:66-73

Parvinen I, Helenius H, Pylkkänen L et al (2006) Service screening mammography reduces breast cancer mortality among elderly women in Turku. J Med Screen 13:34-40

Perry N, Broeders M, de Wolf C, Törnberg S, Holland R, von Karsa L (2008) European guidelines for quality assurance in breast cancer screening and diagnosis. Fourth edition-summary document. Ann Oncol 19:614-622

Puliti D, Duffy SW, Miccinesi G et al (2012) Overdiagnosis in mammographic screening for breast cancer in Europe: a literature review. J Med Screen 19(Suppl 1):42-56

Sarkeala T, Anttila A, Forsman H, Luostarinen T, Saarenmaa I, Hakama M (2004) Process indicators from ten centres in the Finnish breast cancer screening programme from 1991 to 2000. Eur J Cancer 40:2116-2125

Sarkeala T, Hakama M, Saarenmaa I, Hakulinen T, Forsman H, Anttila A (2006) Episode sensitivity in association with process indicators in the Finnish breast cancer screening program. Int J Cancer 118:174-179

Sarkeala T, Heinävaara S, Anttila A (2008a) Breast cancer mortality with varying invitational policies in organised mammography. Br J Cancer 98:641-645

Sarkeala T, Heinävaara S, Anttila A (2008b) Organised mammography screening reduces breast cancer mortality: a cohort study from Finland. Int I Cancer 122:614-619

Törnberg S, Kemetli L, Ascunce N et al (2010) A pooled analysis of interval cancer rates in six European countries. Eur J Cancer Prev 19:87-93

Vainio H, Bianchini F (2002) IARC Handbooks on Cancer Prevention Vol 7. Breast Cancer Screening. WHO/IARC Press, Lyon

Welch GH, Black W (2010) Overdiagnosis in cancer. JNCI 102:605-613

doi:10.1186/2193-1801-3-348

Cite this article as: Sarkeala et al:: Breast carcinoma detection modes and death in a female population in relation to population-based mammography screening. SpringerPlus 2014 3:348.

\section{Submit your manuscript to a SpringerOpen ${ }^{\circ}$ journal and benefit from:}

- Convenient online submission

- Rigorous peer review

- Immediate publication on acceptance

- Open access: articles freely available online

- High visibility within the field

- Retaining the copyright to your article

Submit your next manuscript at $\gg$ springeropen.com 